\title{
Storage of Electronic Files of Federal Agencies That Have Ceased Operation: A Partnership for Permanent Access
}

\author{
Cathy Nelson Hartman
}

Direct all correspondence to: Cathy Nelson Hartman, Documents Librarian: Electronic Resources Coordinator, University of North Texas Libraries, P.O. Box 305190, Denton, Texas 76203-5190<Chartman@library.unt.edu> 


\begin{abstract}
For more than a century, federal depository libraries and the Government Printing Office (GPO) have acted as partners to provide permanent access to government information in tangible media. These partnerships have evolved in the last few years. Built on a century of tradition, new partnerships offer permanent access to electronic files of federal agencies published in nontangible media. This article describes one partnership to store and provide access to the electronic files of agencies that have ceased operation. As the only Web contact for an agency, unique challenges arose when historical publications were frequently requested. Digitized historical publications, bibliographies, and an agency history enhance services for researchers.
\end{abstract}


In 1995, as the Government Printing Office (GPO) began its congressionallymandated transition to an electronic Federal Depository Library Program (FDLP), ${ }^{1}$ the need for methods of assuring permanent access to electronic government information became apparent. Published in December 1995, an initial draft of GPO's strategic plan for the transition identified the need for a coordinated effort to keep agency Web publications in the public domain through the FDLP. The draft strategic plan stated:

When it is determined that an agency no longer intends to provide access at its site, SOD [Superintendent of Documents] will coordinate with the agency to acquire the information and take steps necessary to make it available for long term access through the FDLP. ${ }^{2}$

The final strategic plan, published as part of the Study to Identify Measures Necessary for a Successful Transition to a More Electronic Federal Depository Library Program, ${ }^{3}$ further asserted that GPO, as coordinator of the FDLP, has the responsibility under Title 44, United States Code, $\S 1911$ for providing permanent access to electronic government publications within the FDLP. As used in the Study, permanent access means "that Government information products within the scope of the FDLP remain available for continuous, no fee public access through the program. For emphasis, the phrase 'permanent public access' is sometimes used with the same definition." ${ }^{3}$ Given this interpretation, the Study visualized the solution to the question of permanent access as a network of online partnerships involving federal agencies, GPO, depository libraries, and the National Archives and Records Administration (NARA), with 
GPO playing the coordinating role. ${ }^{4}$ In the Study process, GPO staff initiated a dialog with depository librarians and others to identify reasonable methods for employing partnerships to fill the information gap occurring as federal agencies, having little seeming regard for ongoing use of their information products, were removing important information resources from their Web sites.

Addressing the partnership question at the fall 1995, Depository Library Council meeting, the Depository Library Council recommended to GPO that it "develop model agreements that depository libraries can use when negotiating information dissemination partnerships between federal agencies and depository libraries." The Council maintained that model agreements would offer guidelines to depository libraries and ensure that standards for partnerships were established. GPO concurred that partnerships between agencies and depository libraries should be encouraged. However, GPO also indicated a preference that arrangements for partnerships be made in consultation with GPO staff so that "issues such as no-fee public access, permanent preservation and access, and any proposed restrictions on the use of the information may be addressed early in the process." ${ }^{6}$ In later discussions, Council agreed with GPO's preferred approach. $^{7}$

In late 1996 and throughout 1997, GPO staff communicated with depository librarians about partnerships at various national meetings, including the Federal Depository Library Conference, Council meetings, and sessions of the American 
Library Association's Government Documents Round Table (GODORT). ${ }^{8}$ As a result of these discussions, and from experience gained through the initiation of several prototype partnerships in 1997, the general contours of how partnerships would be configured was worked out. In November 1997, GPO issued a white paper, "Managing the GPO Access Collection: Permanent Access to Electronic Government Information Products," which visualized a "library-like" Permanent Online Collection through which GPO would manage electronic FDLP information products. Two types of partnerships were defined as nodes in this electronic collection: content partnerships and service partnerships. Content partners would store agency publications and provide permanent access to them, with coordination from GPO. Service partners would provide a service or tool intended to assist with the administration of depository libraries. ${ }^{10}$ This article describes the evolution of one content partnership, that established between GPO and the University of North Texas Libraries (UNT) in 1997.

\section{THE UNIVERSITY OF NORTH TEXAS AND GPO PARTNERSHIP}

The proposed GPO content partnerships attracted the strong interest of librarians at the University of North Texas who were actively contemplating how a more electronic federal depository library program would impact the depository library. The librarians reasoned that the responsibilities of a depository library to receive, organize, and provide access to government information products were not changed by the transition in format of the products. Moreover, they 
concluded that GPO's plan for a transition to a more electronic depository library program behooved depository libraries to make their own transition or become obsolete. After reviewing various models for FDLP partnerships and monitoring discussion of partnerships on GOVDOC-L and in Administrative Notes, the decision was reached to pursue possibilities for volunteering as an FDLP partner.

The announcement of the GPO/University of Illinois at Chicago/ Department of State DOSFAN partnership, ${ }^{11}$ a project entailing thousands electronic files and potentially high costs, initially caused some concern about UNT's capacity to serve as a partner. However, UNT documents librarians sincerely believed that there is no justifiable reason that electronic publications should be treated with any less care and concern than documents published in other media, and perceived the partnership scenario to be a logical extension of UNT's ongoing responsibilities as a depository library. The Dean of Libraries concurred. This led to the decision to continue on course in pursuing partnership status, though it was determined that UNT needed to begin with a smaller agency or group of files than the DOSFAN partnership model.

Discussion of a partnership between UNT and the GPO Electronic Transition staff began at the 1997 American Library Association Midwinter Conference. In follow-up discussions, UNT agreed to accept the electronic files of the defunct agency, the Advisory Commission on Intergovernmental Relations (ACIR). 
Congress established the ACIR in 1959, as a "permanent, bipartisan body of 26 members, to give continuing study to the relationship among local, state, and national levels of government. ${ }^{12}$ The Act provided that the Commission would be composed of representatives from federal, state, and local governments and would consider common interests in federal grant programs, proposed legislation, and emerging public problems. In almost forty years of existence, the Commission published recommendations on such topics as the allocation of revenues, simplification of tax laws, and unfunded mandates.

Then in 1995, Congress appropriated, as part of the budget for the fiscal year ending September $30,1996, \$ 784,000$ for the ACIR, "of which $\$ 450,000$ shall be available only for the purposes of the prompt and orderly termination of the Advisory Commission on Intergovernmental Relations." ${ }^{13}$ The electronic files of the ACIR that existed when the agency closed required storage and the provision of permanent public access. The ACIR files met UNT's requirements for beginning a partnership because of the small size of the files, and because, as an agency no longer funded by Congress, the files from the agency would not grow. The acceptance of the ACIR files created a new model for partnerships GPO working with a depository library to provide permanent public access to a group of electronic files that would remain static since the creating agency no longer existed. Having agreed in principal to partner on the ACIR files, the next steps for finalizing the partnership included the completion of a Memorandum of Understanding to be signed by UNT and GPO, and an agreement on the content 
of explanatory information to be placed on a Web page introducing the ACIR collection.

\section{THE MEMORANDUM OF UNDERSTANDING}

In the Fall 1996, the Depository Library Council recommended to GPO that a model Memorandum of Understanding (MOU) between GPO and depository library partners be developed. The Depository Library Council suggested that various issues be addressed in the MOU, including:

- Information stored on partner sites is the property of the federal government and the people of the United States.

- All modifications or enhancements of stored files must not alter accessibility.

- All modifications or enhancements must be documented.

- Format of files should comply with industry standards.

- Backups of stored files must be maintained.

- Contingency plans must be made for cases where a library or agency partner becomes unable to continue the partnership. The partner provide GPO with the stored files, including any enhancements or modifications made to the files.

- Adherence to ADA compliant formats should be a priority.

- GPO's role as the coordinator of the partnership program should be clearly outlined. ${ }^{14}$ 
The proposed MOU for the ACIR partnership outlined each partner's responsibilities in the agreement and included all of the above-recommended elements. The following additional issues were also covered:

- Free, unrestricted access and/or re-dissemination of the files were required. Reasonable fees to recover costs could be charged for copying files to any tangible media.

- Technical requirements comprised a minimum number of simultaneous connections, minimum allowed server down time, persistence of the Internet address, and provision of reasonable security to assure the authenticity of the files.

- Recording and analysis of data to measure usage of the files was required only upon demand by GPO.

- If either partner initiated termination of the partnership, a method for notification and transfer of the files and any accompanying software was outlined.

- Costs associated with maintenance of the files, provision of permanent access, and security of the files were delegated to the partner library.

The elements of the MOU paralleled established requirements of depository libraries receiving traditional government information products. For instance, information products in the Federal Depository Library Program belong to the federal government and the people. Likewise, termination of a depository library agreement has always included the option for GPO to request the return of 
information products received as part of the Program. Traditional depository libraries also provided no-fee access to information, data reporting, and maintenance and security for the collection. ${ }^{15}$ Differences between the MOU and traditional requirements centered on a few technical issues. Remote users accessing the files through the Internet must be accommodated, and measures to copy the files regularly to an appropriate storage medium and locate them in a separate physical facility must be taken. The responsibilities stated in the Memorandum of Understanding were judged to be reasonable and acceptable, and the partnership was announced in the October 1997 issue of Administrative Notes.

\section{SPECIAL CONCERNS FOR ACCOMPANYING EXPLANATORY INFORMATION AND FILE INSTALLATION AND MAINTENANCE}

To introduce the ACIR files placed on the UNT server, an explanatory Web page was created to state the:

- Purpose of the site - provision of permanent public access to the files of a government agency.

- Federal program under which the site was created - the Federal Depository Library Program.

- Existence of a partnership arrangement.

- Government agency regulating the partnership - GPO, and 
- Fact that the ACIR no longer existed and that the files contained on the site were exactly as they appeared on the agency's World Wide Web site when the agency closed.

This information clarified the fact that, through UNT, the FDLP provided permanent public access to the ACIR electronic collection, as opposed to the preservation services provided by NARA. The statement of the partnership agreement between UNT and GPO assured users that the site was an official site. Information was also provided concerning the closure of the ACIR, explaining the defunct status of the agency; it was clearly explained that the files here were as they appeared on the ACIR Web site when the agency was closed.

The decision to maintain the files as they existed when the ACIR closed led to further questions. Discussions ensued about the maintenance of links from the ACIR files to other Web sites, about the presence of an electronic mailing address for the submission of solicited comments on ACIR reports, and about other minor issues as they arose. Three important assumptions considered in answering these questions were: the files were provided to facilitate permanent access and were not archival in nature; users of the site might be confused by outdated links for contacting the closed agency; and any changes to this site should not affect the content or appearance of the files.

Answers to some of the questions were unique to ACIR, owing, in part, to the defunct status of the agency. For example, in consideration for users clicking on 
the link to ACIR electronic mail, the HTML scripting was redirected from a defunct e-mail address to link to a page that explained the status of the ACIR and which offered a link to the introductory information about the agency and the partnership. At the same time, however, links from the ACIR files to other Web sites were left unchanged since updating the links would, over time, potentially change the content of the files as those Web sites disappeared or changed. Both of these decisions - one involving a slight change to the scripting and the other involving a decision not to change - were supported by the FDLP concept of permanent access, which allows for some modification in format to improve access, as opposed to NARA efforts to preserve information fully in its original context.

\section{PARTNERSHIP TO PROVIDE PERMANENT ACCESS TO THE FILES OF A CLOSED GOVERNMENT AGENCY}

When UNT and GPO reached agreement on the terms of the Memorandum of Understanding and on the introductory material, appropriate officials at GPO and UNT signed the MOU, and GPO's staff tested the functionality of the site. The unique issues involved when assuming responsibility for the electronic files of a closed government agency were gradually realized. ACIR published many documents over almost a half century, and initially only a few of the publications were available on the partnership site. By hosting the ACIR Web site, UNT became the most visible contact in the world for ACIR documents. Rather unexpectedly, students, researchers, local and state government employees, 
and commercial interests in the United States, Europe, and Japan began to ask to purchase or borrow ACIR documents from the UNT collection. Although systematic statistics were not collected in the first months of the partnership, evidence from existing records indicates that approximately eight to ten requests were received each month.

In an effort to bolster the collection of ACIR resources to meet this demand, the UNT staff assessed the UNT ACIR paper collection by comparing it to bibliographies of publications included in the ACIR periodical, Intergovernmental Relations. The Federal Depository Library Program "Needs and Offers Lists" was also consulted to collect titles not available in the UNT collection and duplicates of other ACIR documents. Beyond this increased work load to identify and acquire ACIR documents, staff found that inaccurately cited or obscure references to ACIR materials required additional work to honor requests, and the delivery of the information to fill requests added costs. Furthermore, as requests for ACIR publications increased, concern arose about lending the only available UNT copies of documents to patrons at distant sites. For the protection of the paper ACIR collection and to relieve staffing issues, it quickly became apparent that another means of providing access to the older ACIR publications was required. Patron demands for fast service suggested that a solution must provide quick access to the older ACIR documents, and staffing issues required a solution that allowed distant patrons to find the required information without local intervention. 


\section{ENHANCEMENTS TO THE PARTNERSHIP SITE}

The first enhancements UNT made to the ACIR partnership collection were informational and bibliographic in nature. To enhance the informational content of the partnership, a brief history of ACIR was added that cited relevant congressional acts and United State Code sections involved in the evolution of the ACIR from early commissions to the more permanent ACIR. This history also supplied additional information about the agency by tracing the chronology of important events in its creation and dissolution. To enhance user ability to identify ACIR publications, a comprehensive bibliography of ACIR and precursor agencies' publications was compiled to assist users in locating ACIR material and verifying citations. Organization of the bibliography followed the model of ACIR-published bibliographies since researchers in the field of intergovernmental relations would be accustomed to such an organization. For items in the UNT collection, links were created in the bibliography to the USMARC records contained in the Libraries' online catalog, providing access to further descriptive material. For the publications available in the electronic collection, hyperlinks were added to provided immediate access to the full text of the documents.

The bibliography and brief history of the agency furnished additional access points to the electronic files and the paper collection of ACIR publications. However, providing access to the titles in the paper collection required loaning 
the documents. Loaning risked loss or damage to the documents and could restrict usage of a document to only one user for several weeks. One possible solution, digitization of the documents, could offer multiple simultaneous users access, would not risk damage or loss of only copies, and could supply users with the desired quick access to the text of the documents. UNT decided to investigate options for digitizing the paper ACIR collection to resolve these problems.

\section{BALANCING COSTS OF DIGITIZING WITH LEVEL OF ACCESS}

Given concerns about the physical integrity of ACIR materials and the ongoing demand from remote sites for access to ACIR publications, UNT considered strategies for providing researchers and the public with high-quality access to the important publications of the ACIR at a reasonable cost. The primary tactics considered for servicing demands on ACIR publications were the provision of Internet access to two important ACIR serial publications and the development of a cost-effective process for presenting, on the Internet, extensive collections of electronic files. Access to the text of the scanned documents was an important consideration because it would enable searching of the text.

Investigation of possible file types revealed the high accessibility of HTML files. However, the costs stated in the project report of the AMIGOS funded study at Oklahoma State University, A Digital Challenge: Bringing Kappler's Indian 
Affairs: Laws and Treaties to the World Wide Web, clearly showed that creation of HTML files from scanned text was a costly, time-intensive effort. ${ }^{17}$ Furthermore, scanning of documents as simple graphic files was considered problematic because it allowed no access to the text. And, use of Optical Character Recognition (OCR) software with graphic files always resulted in inaccuracies because the OCR software could not interpret every character. Hence, the combination of scanned images and inexact OCR text provided in PDF files seemed the optimal solution. This file type, called Portable Document Format (PDF), held potential for balancing the issues of cost and accessibility of digitized text. Basically, when the OCR software interpreted the text inaccurately, the view of the graphical representation of the page allowed the user to verify the text.

A grant proposal submitted to AMIGOS, Inc., in early 1998, requested funding for a pilot project to assist with development of a low-cost method for digitizing that would balance costs with levels of access. In the project design, UNT proposed that the digitization project would be accomplished by outsourcing for highspeed, quantity scanning of two ACIR serial publications. PDF files would be supplied to UNT by the vendor providing the scanning services, and further enhancement of the files, such as internal links from indexes and contents pages of the document, would be added at UNT. UNT would develop a procedures manual to document the process and assist with training for future projects. Data collected for analysis would determine the per-page cost of digitizing using 
the procedures developed during the pilot project. AMIGOS announced funding of the project in May 1998.

Work began on the project in August 1998 and achieved completion in December 1998. Outsourcing of the scanning provided the project with quality PDF files at a reasonable cost, and analysis of the data collected showed that a reasonable per-page cost was achieved. ${ }^{18}$ The PDF files combined searchability and a graphical view of each page as it appears in the print version of the document. Owing to additional funding that became available, a total of more than 8,000 pages were digitized in this phase of the project. Further funding to complete the digitization of the remainder of the ACIR collection is required, but all volumes of the two ACIR serial publications, Intergovernmental Relations and Significant Features of Fiscal Federalism, may currently be accessed on the Internet through the UNT FDLP partnership.

\section{CONCLUSION}

The agreement between GPO and UNT, originally based on the defunct ACIR agency, has recently been expanded to a partnership for the storage and provision of permanent public access to the electronic files of additional government agencies that have ceased operation. The revised Memorandum of Understanding provides an appendix that lists all of the collections included in 
the partnership. In addition to the ACIR files, currently the partnership includes the files of the:

- Commission on Structural Alternatives for the Federal Court of Appeals

- International Competition Policy Advisory Committee (ICPAC)

- National Civil Aviation Review Commission, and

- Office of Technology Applications - Highway TechNet

The ACIR collection continues to be unique in that it remains the only agency in the partnership with a long history of publishing.

For more than a century, strong partnerships between GPO and depository libraries have provided an effective means of delivering permanent access to government information to the citizens of this country. With the transition to electronic publishing of government information, permanent access to electronic government documents is in question. Depository libraries are uniquely positioned to continue their historical role of storing and making available government information products by initiating permanent access FDLP partnerships with GPO. To fill this role, depository libraries must change their perceptions of storage space to include magnetic media in addition to shelf or cabinet space. They must also evolve in their perceptions of their patron base. Now, in addition to serving citizens in their region, depository libraries may provide access to government information for all citizens of the United States and for people around the world. 
Finally, and perhaps most importantly, the UNT/FDLP partnership on ACIR and other defunct agencies has demonstrated that depository libraries as FDLP partners can significantly and substantially enhance access to federal government information. UNT has identified, scanned, and enhanced access on the Web to scores of ACIR publications. Other depository libraries should recognize that this sort of enhancement is not unfamiliar. Depository libraries have designed specialized handouts and bibliographies to assist local clients to meet their government information needs for years. Yet, the Web significantly increases the impact of these specialized services, virtually extending them to the entire world. This has been the case in UNT development of the extended ACIR bibliography and the digitizing of key ACIR publications for Web access. 


\section{NOTES AND REFERENCES}

1. Legislative Branch Appropriations Act of 1996 (P.L. 104-53) (109 Stat. 514) 1995.

2. Government Printing Office, "The Electronic Federal Depository Library

Program: Transition Plan, FY 1996 - FY 1998," Administrative Notes, 16

(December 29, 1995). Available:

http://www.access.gpo.gov/su_docs/dpos/transit.html.

3. Government Printing Office, Study to Identify Measures Necessary for a Successful Transition to a More Electronic Federal Depository Library Program (Washington, D.C.: Government Printing Office, June 1996), p. E - vi.

4. Ibid.

5. Depository Library Council to the Public Printer, "Recommendations from the Fall Meeting, October 16-18, 1995 Memphis, Tennessee," Administrative Notes, 17 (May 15, 1996). Available:

http://www.lib.umich.edu/libhome/Documents.center/adnotes/1996/170796/an17 07b.txt.

6. Ibid. 
7. Depository Library Council to the Public Printer, "Recommendations and Action Items of Depository Library Council to the Public Printer Fall 1996 Council Meeting," Administrative Notes, 18 (April 15, 1997). Available: http://www.access.gpo.gov/su_docs/dpos/ad041597.html.

8. See Administrative Notes issues published in 1995-1997. Speeches, handouts, recommendations from Council, and other items document the discussions.

9. Government Printing Office, "Managing the GPO Access Collection:

Permanent Access to Electronic Government Information Products," Administrative Notes, 18 (November 25, 1997). Available:

http://www.access.gpo.gov/su_docs/dpos/wpaper.html.

10. Government Printing Office, "Electronic Transition Staff Update Fall 1997 Depository Library Council Meeting October 20 - 23, 1997 Managing GPO Access as a Collection," Administrative Notes, 18 (November 25, 1997). Available: http://www.access.gpo.gov/su_docs/dpos/ad112597.html.

11. Government Printing Office, "GPO, State Department, University of IllinoisChicago Join in FDLP Partnership," Administrative Notes, 18 (July 15, 1997). Available: http://www.access.gpo.gov/su_docs/dpos/ad071597.html.

12. P.L. 86-380 (73 Stat 703) 1959. 
13. P.L. 104-52 (109 Stat. 468) 1995.

14. Government Printing Office, "Recommendations and Action Items of Depository Library Council to the Public Printer Fall 1996 Council Meeting Salt Lake City, Utah," Administrative Notes, 18 (April 15, 1997). Available: http://www.access.gpo.gov/su_docs/dpos/ad041597.html.

15. Government Printing Office, Instructions to Depository Libraries Revised April 1992 (Washington, D.C.: Government Printing Office, 1992). Available: http://www.access.gpo.gov/su_docs/dpos/instruct.html.

16. Government Printing Office, "GPO and University of North Texas Create FDLP Partnership," Administrative Notes, 18 (October 15, 1997). Available: http://www.access.gpo.gov/su_docs/dpos/ad101597.html\#7.

17. Suzanne Holcombe, A Digital Challenge: Bringing Kappler's Indian Affairs: Laws and Treaties to the World Wide Web (Stillwater, Oklahoma: Oklahoma State University, 1997). Available: http://www.library.okstate.edu/kappler/intro.htm\#Evaluation

18. Cathy Nelson Hartman, "Digitizing Collections of Government Documents: Options, Processes, and Costs," in Proceedings of the $8^{\text {th }}$ Annual Federal 
Depository Library Conference (Washington, D.C.: Government Printing Office, 1999), pp. 45-59. 